\title{
Ventricular septal defect and mitral regurgitation secondary to myocardial infarction
}

Sir:

We read with interest, the article by Dr. Fleming on ventricular septal defect and mitral regurgitation after a myocardial infarction (Vol. 35, p.344). We have recently performed left and right heart catheterization to include coronary arteriography on 4 patients with ventricular septal defects after acute myocardial infarction. In none was angiographically detectable mitral insufficiency found despite prominent pulmonary venous wedge and/or left atrial V waves in all 4 patients. It is our feeling that the $V$ wave represents a filling phenomenon and is not of diagnostic significance in the presence of ventricular septal defect after acute myocardial infarction. Usually, these patients are in profound left-sided failure and a V wave in this instance is usually rather large. We have not observed a patient with a proven ventricular septal defect and mitral regurgitation secondary to a myocardial infarction and suspect that these two lesions together are not compatible with life. We are presently writing up our experience with the four above-mentioned patients. Of particular interest in this regard is an article which appeared in the New England fournal of Medicine (1973), 287, 1024, in which Drs. Meister and Helfant found the $\mathrm{V}$ wave to be of 'diagnostic importance' in mitral insufficiency in a patient who had a myocardial infarction. Since the murmur of a ventricular septal defect after a myocardial infarction mimics that of mitral insufficiency very well (possibly because the defect is usually near the apex of the ventricle), the only way we feel that one can separate these two

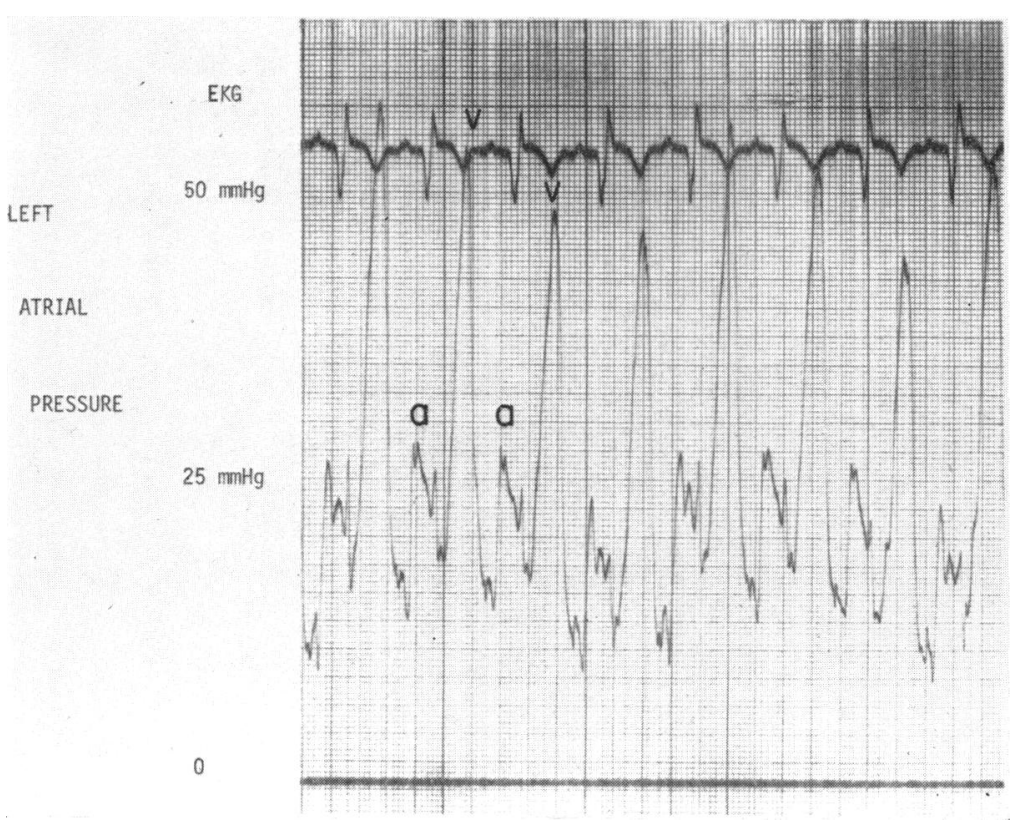

FIG. 
phenomena is with a complete heart catheterization. A right heart catheterization showing oxygen step-up does not rule out in any way the presence of mitral insufficiency despite a large $\mathrm{V}$ wave as we have previously shown. However, we still feel that since no proven case of these two lesions has occurred together after myocardial infarction, that the presence of a ventricular septal defect may well negate the presence of mitral insufficiency.

We were surprised that the authors in the paper mentioned in your journal felt that mitral insufficiency was of great degree when they never proved that it was there at all. That paper points out well the necessity for complete cardiac evaluation before conclusions can be made. We would strongly suggest that they restudy their patient as the presence of mitral insufficiency seems unlikely from our experience.

We have enclosed for your interest a copy of left atrial recording in one of our patients with a ventricular septal defect after myocardial infarction (Fig). The wedge and left atrial V waves approached $50 \mathrm{mmHg}$ and no mitral insufficiency was seen during left ventricular cineangiography.

Charles F. Bethea, Robert H. Peter, Victor S. Behar, and Yithong Kong, Cardiovascular Laboratory, Duke University Medical Center, Durham, North Carolina 277ro, U.S.A.
This letter was shown to the author of the paper who replies as follows.

Sir:

I welcome the opportunity of seeing the letter from Dr. Bethea and his colleagues and, in view of their data on 4 cases, I must agree that the diagnosis of mitral incompetence in my patient is more than suspect.

I have carefully reviewed this patient - now well at the age of 68 years and eight years after his myocardial infarction - and it would be quite unjustifiable on ethical grounds to reinvestigate him by invasive techniques. In his case recent echocardiographic studies have shown normal movement of the anterior mitral leaflet, but we were unable to pick up the posterior leaflet. Therefore, this technique gave no positive evidence of mitral incompetence. Septal movement was abnormal and in keeping with a ventricular septal defect.

I look forward to seeing Dr. Bethea and his colleagues' full report on their cases.

H. A. Fleming, Papworth Hospital, Papworth Everard, Cambridge $\mathrm{CB}_{3}$ 8RE. 